\title{
The COMParative ANALYSiS OF SAFETy IN THE CZECH REPUBLIC AND IN ABROAD
}

\section{Katerina Vichova \& Martin Hromada \& Martin Ficek \& Michal Gracla}
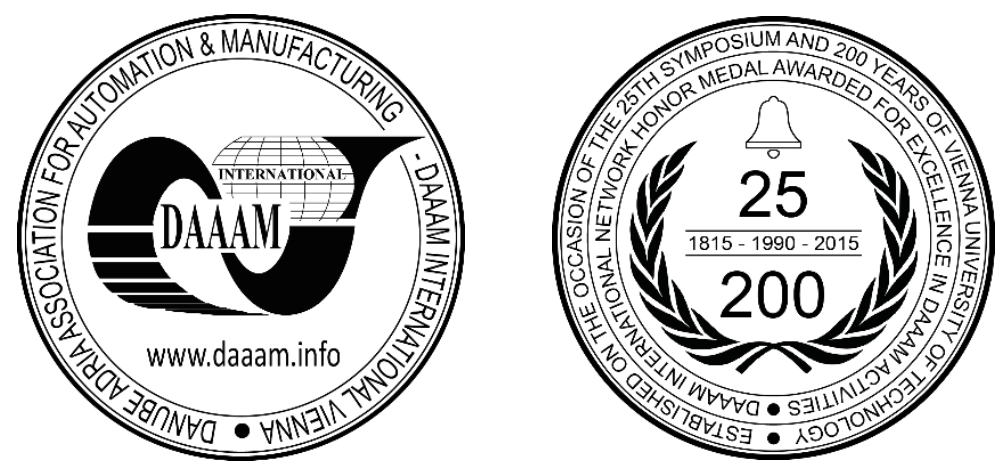

This Publication has to be referred as: Vichova, K[aterina]; Hromada, M[artin]; Ficek, M[artin] \& Gracla, M[ichal] (2018). The Comparative Analysis of Safety in the Czech Republic and in Abroad, Proceedings of the 29th DAAAM International Symposium, pp.1181-1186, B. Katalinic (Ed.), Published by DAAAM International, ISBN 978-3-90273420-4, ISSN 1726-9679, Vienna, Austria

DOI: $10.2507 / 29$ th.daaam.proceedings. 170

\begin{abstract}
Many extraordinary events and crisis situations threaten the whole world. These events are natural, anthropogenic threats, terrorism, and others. These have an impact on the lives, health, and assets of citizens, but also on the critical infrastructure and economy of the country. The goal of each state is to protect its citizens and infrastructure. One sector of critical infrastructure is also healthcare. It is therefore essential that the health service can perform its function, even in an emergency or crisis.

In recent years, we can see an increasing number of crisis, resulting in more significant loss of life and impact on the economy of a given country. In spite of the efforts and measures of each country's government to reduce the impact of the crisis, this trend has not been avoided. This trend is observed at all levels - in regions, in the Czech Republic, but also in the whole world. The crisis of natural character ordinarily has the so-called cascade effect, which causes other extraordinary events. An example may be wind turbulence, resulting in a power outage. The aim of this article is to perform a comparative analysis of the impact of crisis situations on the lives of the population and the economy of the country.
\end{abstract}

Keywords: crisis; power outage; Czech Republic; threats; hospital

\section{Introduction}

In today's world, the term "extraordinary events" and "crisis" are frequently framed. The Czech Republic was hit by a notable flood that caused significant damage to citizens' property and required human sacrifices in 1997. This critical situation has revealed a considerable shortcoming. The rescue units of the state - the Fire Rescue Service (FRS), the Emergency Medical Service (EMS) and the Police of the Czech Republic (PCR) did not have a situation coordinator. The laws on crisis management, the so-called Criminal Law Package, came into force in 2000. These laws have led to the implementation of the Joint Rescue System (JRS) and the creation of support for crisis management in the Czech Republic. These laws define, among other things, an extraordinary event and a crisis. An extraordinary event means the harmful effects of forces and phenomena caused by human activities, natural influences, as well as accidents that endanger life, health, property or the environment and require the execution of rescue and disposal operations [1]. Crisis is an extraordinary event under the Joint Rescue System Act, Critical Infrastructure Disruption, or other hazards that state the state of danger, state of emergency or state of emergency [2]. 
Nobody knows when extraordinary event or crisis will strike. This issue deals with security futurology. The security futurology is the science of the future, which deals with the theory, study and creation of variants of possible developments in the security situation [3]. Security futurology includes segments of security - cyber security, data security, security, security, security, security, etc. [4].

The consequences of extraordinary situations and crisis lead to direct and indirect threats to the lives, health and the environment in which we live [5]. The objective of each country is to protect its citizens, their health, property and the environment. For these purposes, countries are developing security strategies that focus on selected security areas. Not only in the Czech Republic but also abroad, an increase of extraordinary events and the crisis is observed. Everyday people hear about the events that have happened around the world. According to Rehak, the planet Earth and its population are currently exposed to a whole range of dangers. There are natural disasters, industrial accidents, social, religious and ethnic conflicts frequently associated with wars, and escalating the threat of terrorism that knows no boundaries [6]. Sena notes that natural disasters caused by extreme weather events have increased in recent years [7]. Natural disasters are among the most expensive, deadly and feared events of [8] humanity that have a significant impact on the general public [9] and have the potential to kill thousands of people within minutes [10]. Over the past twenty years, more than three million families (at least 800 million people) have suffered natural disasters worldwide and cost more than $\$ 500$ billion [11].

Natural disasters may also result in other extraordinary events. These may be cascading effects. One of them is a disruption of the power supply (blackout). The term blackout is defined as a total power outage in a large area. Furthermore, this term refers to the moment when there is a breach of the balance between generation and consumption of electricity and when the security of supply is compromised. [12]

This outage interferes not only with the lives of people but also with the operation of the whole state, especially with the economic development of the affected area. [13] The particular feature of the blackout is that the secondary consequences of the outage are many times greater than the effects on the plants for the production, transmission, and distribution of electricity. The cause of this is dominoes that arise from the interconnection of the entire critical infrastructure. [13] Power outages can cause significant problems not only in the households but also in the critical infrastructure sectors mentioned, for example in the health sector.

Here, it is essential that patients in a hospital requiring permanent care of the devices have an electrical supply. A hospital employee cannot afford a power failure during operations. Even the children in the incubator must not be denied the supply of basic living needs. The aim of this paper is to analyse security threats in the Czech Republic and abroad.

\section{Methodology}

Four methods of scientific work have been used in this article. The method of analysis is used because it uses the principles of logic to achieve the set goal and provides the framework to explore the principles of safety. The induction method was used, where this method serves to examine the fact of creating a hypothesis from the obtained points. Comparison method allows to evaluate and analyse national strategy and disasters in the Czech Republic and abroad. Finally, the SWOT analysis was used in this paper. SWOT analysis was used for the evaluation of safety situation in the Czech Republic and abroad.

\section{Analysis of crisis in the whole world}

As already mentioned in the introduction, the increasing number of crisis is observed. This is also evident from the references. These situations affect not only the lives and health of citizens, but also the economic impact. The following chapter focuses on comparing crisis around the world with impact analysis.

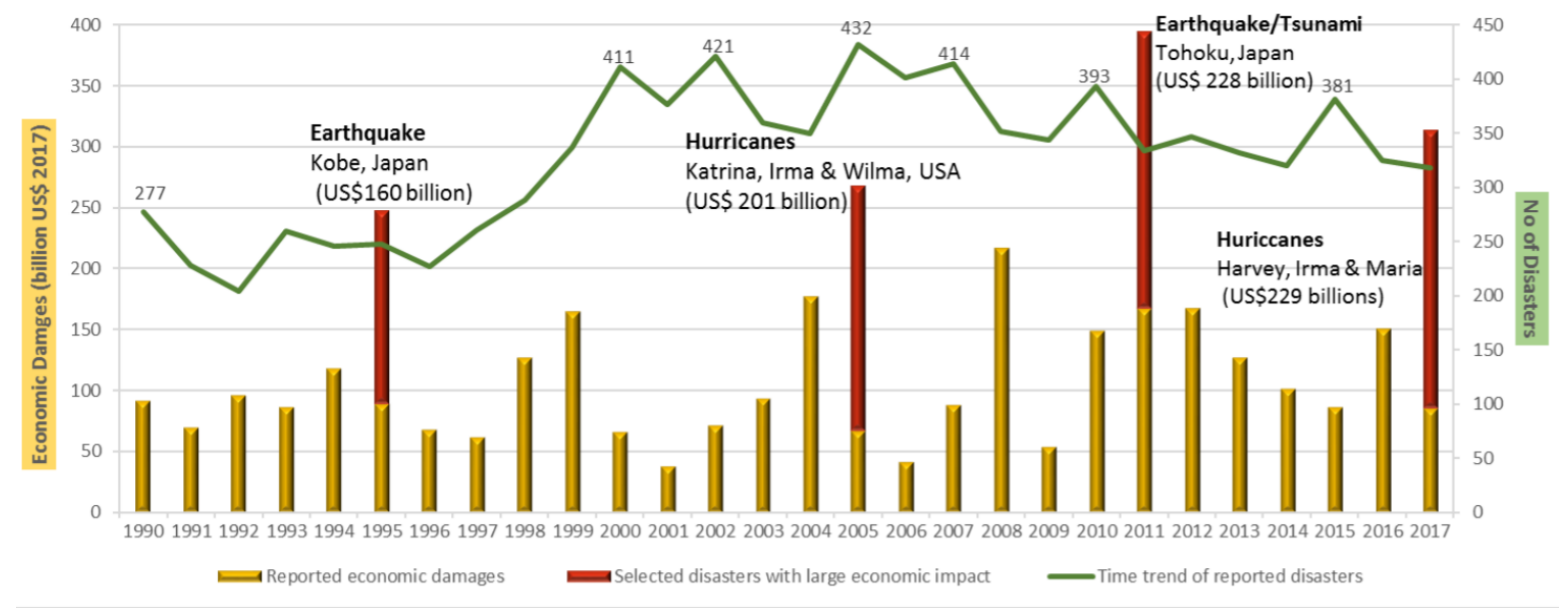

Fig. 1. Time trend of reported disaster [14] 
Figure 1 shows the time trend of reported disaster and economic impact on the countries. As can be seen, the green line shows the time trend of reported disaster from 1990 to 2017 . We can see, that there is the significant rise in the disaster from 1990 to 2000 . This rise is about one hundred situations in ten years. In the following ten years, there was the similar number of the situations - about four hundred. And finally, in the last seven years, there was the slight decrease of the disasters. In the previous year, 2017 there were 335 reported disasters.

These situations have the significant impact on the economy of the state. There we cannot see the trend by the disasters. There are some disasters, which have the significant economic impact. It was the earthquake in Japan (1995), hurricanes Katrina, Irma and Wilma in the USA (2005), earthquake and tsunami in Japan (2011) and Hurricane Irma, Maria and Harwey (2017).

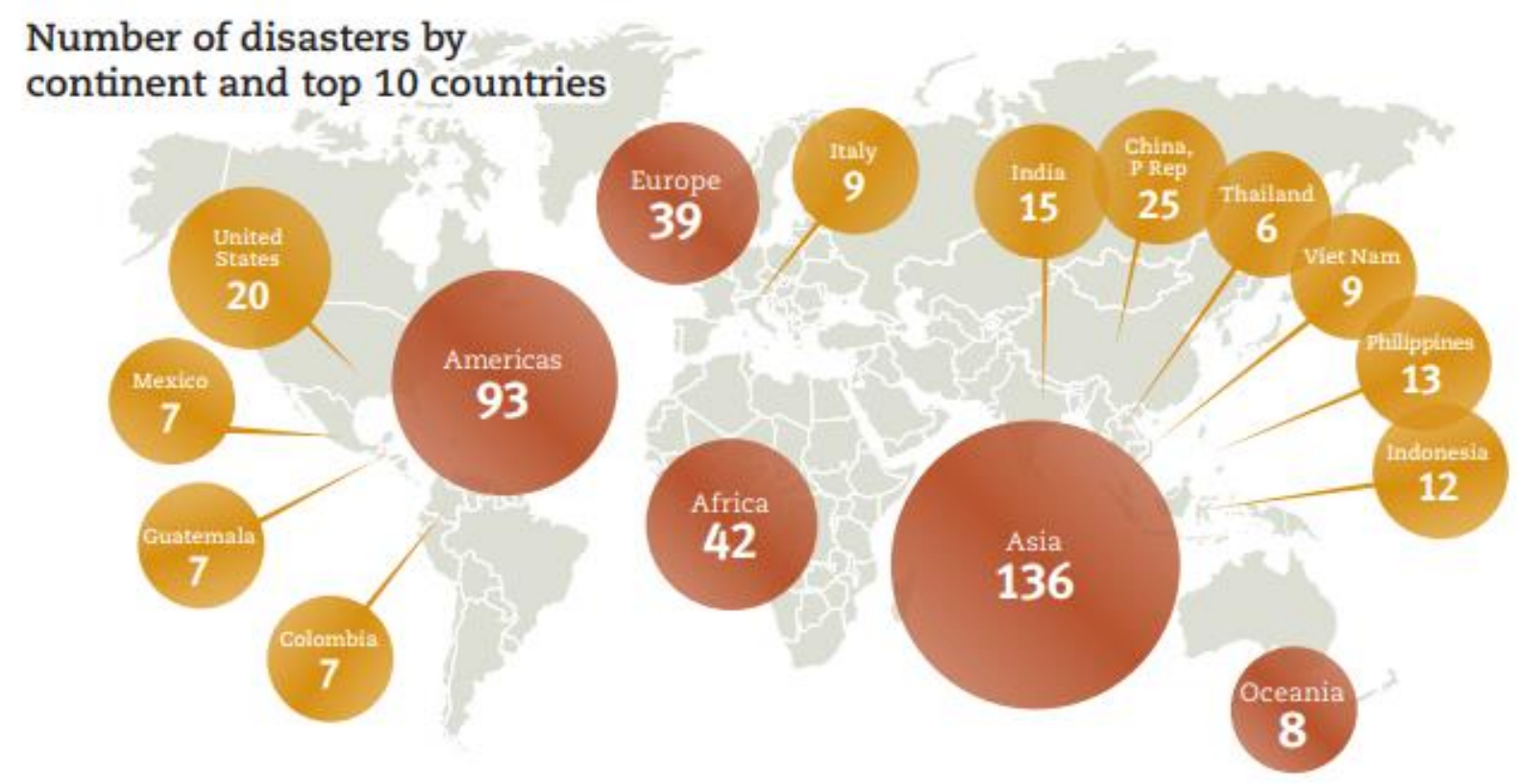

Fig. 2. Number of disasters by continent and top 10 countries [14]

Figure 2 shows the number of disasters by the continent and the top ten countries. As can be seen, the most affected continent was Asia, with 136 situations India, China, Thailand, Vietnam, Philippines and Indonesia in 2017. The second most affected continent was America with 93 situations in 2017. And in Europe was reported 39 situations and the most affected country was Italy.

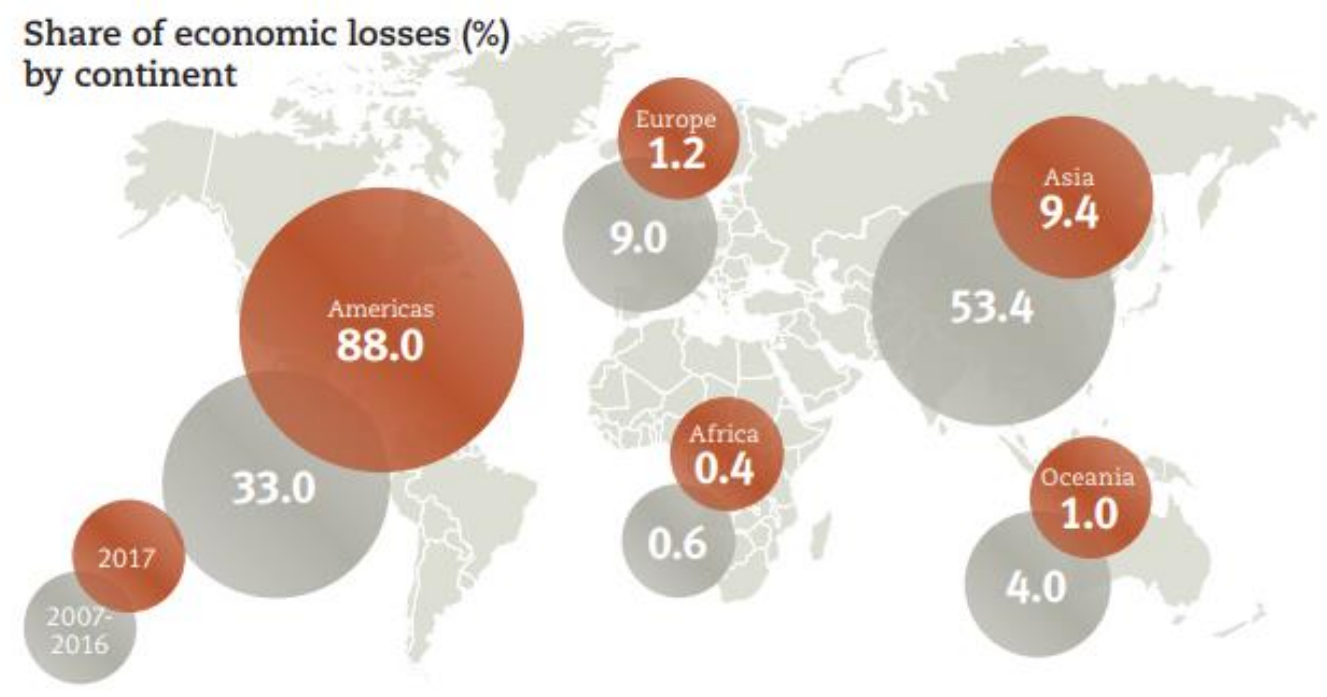

Fig. 3. Share of economic losses by continent [14]

Figure 3 shows the share of economic losses by continent. As can be seen, the most significant economic losses were in America. There was 88 percent of economic losses from the whole world in 2017. 


\section{Security analysis}

Each country has its specific threats. Besides, each state processes a security strategy in which it identifies the most likely risks to its country. There is the Security Strategy of the Czech Republic, 2015, which defines these threats.

- Weakening the cooperative security mechanism and political and international legal obligations in the field of security;

- Instability and regional conflicts in the Euro-Atlantic area and its surroundings;

- Terrorism;

- Dissemination of weapons of mass destruction and their means of delivery;

- Cyber-attacks;

- Negative aspects of international migration, extremism and an increase in Internet and social tensions;

- Organized crime, in particular, serious economic and financial crime, corruption;

- The threat to critical infrastructure functionality;

- Interruption of supply of strategic raw materials or energy;

- Disasters of natural and anthropogenic origin and other emergencies [15].

Threat types were analysed according to the acceptability of risk. This analysis was identified 22 kinds of threats for which a crisis can be reasonably expected.

\begin{tabular}{|c|c|c|}
\hline Category & & Types of threats \\
\hline \multirow{9}{*}{ Naturogenic } & \multirow[t]{6}{*}{ Abiotic } & Long-term drought \\
\hline & & Extremely high temperatures \\
\hline & & Flooding flood \\
\hline & & Extreme collisions \\
\hline & & Extreme wind \\
\hline & & Flood \\
\hline & \multirow[t]{3}{*}{ Biotic } & Epidemic \\
\hline & & Epiphany \\
\hline & & Epizooty \\
\hline \multirow[t]{13}{*}{ Anthropogenic } & \multirow[t]{10}{*}{ Technogenic } & Disruption of large-scale food supplies \\
\hline & & Disturbance of the functionality of major electronic communications systems \\
\hline & & Disruption of Critical Information Infrastructure Information Security \\
\hline & & Special flood \\
\hline & & Leakage of hazardous chemical from stationary equipment \\
\hline & & Disruption of large-scale drinking water supply \\
\hline & & Disruption of large-scale gas supplies \\
\hline & & Broken supply of large scale oil and oil products \\
\hline & & Radiation crash \\
\hline & & Disruption of large-scale electricity supplies \\
\hline & \multirow[t]{2}{*}{ Sociogenic } & Large-scale migration waves \\
\hline & & Violation of the legality of a large scale \\
\hline & Economic & The disturbance of large-scale financial and foreign exchange economies \\
\hline
\end{tabular}

Table 1. Threats in the Czech Republic [16]

Table 1 shows types of threats, which was identified for the Czech Republic. As can be seen, there are many threats naturogenic - abiotic. How we mentioned in the introduction, these situations can cause other emergencies.

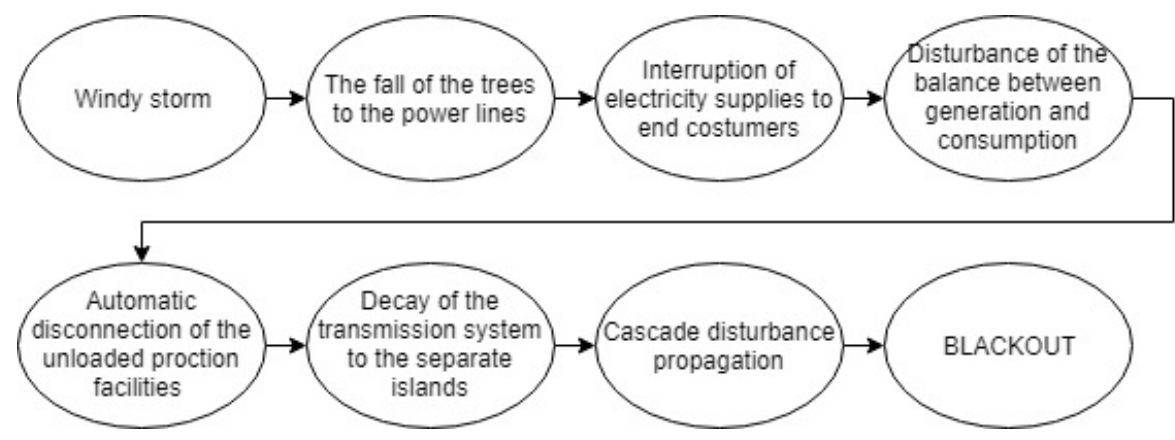

Fig. 4. Cascading effect 
Figure 4 shows the cascading effect of the windy storm which can cause the blackout. The diagram shows the successive events that affect each other. In connection with foreign affairs, it can be stated that security threats are defined which affect the lives, health, the property of the citizens and the environment. The European Union drew up an Internal Security Strategy for the European Union (ESD) defining threats - the main challenges for the EU's internal security in 2010 .

- Terrorism;

- Organized crime;

- Cybercrime;

- Cross-border crime;

- Natural or human-made disasters [17].

In the comparative with the Czech Republic, we can say, that there are the same security threats. There is extra threats cross-borded crime. Nowadays there are enormous increase of terrorism in the Europe. However, natural disasters are the most occurring.

Concerning the US, the President of the United States of America issues the National Security Strategy of President Trump, stating the US's position on security. One is that the US must take steps to respond quickly to the needs of the American people in the event of a natural disaster or attack on the country. They must build a culture of readiness and resilience within government functions, critical infrastructure, and economic and political systems. Although the US government is trying, it cannot prevent all the dangers of the American people. But it can help Americans remain resilient to the difficulties. Resilience includes the ability to withstand and quickly recover from intentional attacks, accidents, natural disasters as well as unconventional stress, shocks and threats to our economy and the democratic system. In the event of an emergency, federal, state and local agencies must carry out essential functions and have established plans to ensure the continuation of the constitutional form of government [18].

Based on the security analysis we can say, that the common problems are natural disasters and protect of critical infrastructure. Critical infrastructure ensure the territory by basic services necessary for humans' live as there are energy, water, food, information etc. [19]. Finally, we used SWOT analysis for the evaluation of safety situation in the Czech Republic and abroad.

\begin{tabular}{|l|l|}
\hline Strengths & Weaknesses \\
\hline$\bullet \quad \begin{array}{l}\text { The development of security strategy in the } \\
\text { countries. }\end{array}$ & $\bullet \begin{array}{l}\text { The inalienability of the situation with natural } \\
\text { disasters. }\end{array}$ \\
$\begin{array}{l}\text { Preparing Critical Infrastructure Protection } \\
\text { Plans. }\end{array}$ & Threats \\
\hline Opportunities & $\bullet \quad$ Finance. \\
& $\begin{array}{l}\text { Use of information systems, evaluation tools and } \\
\text { forecasting systems to detect emerging crisis. } \\
\text { Evaluate each situation which can happen. }\end{array}$ \\
\end{tabular}

Table 2. SWOT analysis

\section{Discussion}

The aim of this paper was to analyse security threats in the Czech Republic and abroad. There was the hypothesis that there is the increasing number of emergencies and crisis. This hypothesis was confirmed based on the references of the authors from the Czech Republic and abroad. This hypothesis was established with the database, which shows the increasing number of crisis in the whole world.

There was used SWOT analysis, where we analyse the situations with security threats. As the opportunities, we say the use of information systems, evaluation tools or forecasting systems to detect emerging crisis. Based on this opportunities, we have one proposal to the evaluation system of the preparedness hospitals to the power outage (blackout). As was said in the paper, the crisis caused the next emergencies. For example, windstorm can cause the power outage. It can be the enormous problem for the hospitals. This situation must be solved with the aggregate, which gives energy to the hospital. However, there is one problem. Each hospital has the different amount of fuel.

The aggregate must have fuel for the energy production. Based on the different amount of fuel we do not know; how long our aggregate will produce the energy. Supply of fuel in the event of a power outage for hospitals is dealt with by the regional authority. The region's endeavour is for hospitals to work even in times of crisis. Therefore, the Regional Authority provides fuel for hospitals. To determine the need for fuel for hospitals, but also for other health care facilities (homes for the elderly, social houses, etc.), an evaluation system is being prepared to determine the fuel reserves in these facilities. 
Based on this system we can get an overview of the situation in our region based on the application, which show us the situation with the amount of fuel in the hospital. Then the regional authority may address the supply of fuel to the necessary hospitals. There can be problem with the private hospital. These hospitals are not under regional authority. The situation would have to be resolved by agreements before the application was started.

\section{Conclusion}

The aim of this paper was to create a comparative analysis of safety in the Czech Republic and abroad. This paper introduced security threats of the Czech Republic, European Union and part of the strategy of the USA. Based on the comparison we can say, that each strategy highlights natural threats. This part was described and shown in the next part of the paper based on the International Disaster Database. In the last part of the paper, in the discussion, we propose the new evaluation system, which can evaluate preparedness hospital for the power outage.

\section{Acknowledgement}

This research was supported by the Internal Grant Agency of Tomas Bata University in Zlín, IGA/FAI/2018/014 and IGA/FAI/2018/001. Next was there research supported by Department of Security Engineering, Faculty of Applied Informatics.

\section{References}

[1] Czech Republic. Act No. 239/2000 Coll. about Joint Rescue System, In. Collection of Law.

[2] Czech Republic. Act No. 240/2000 Coll. about Crisis Management, In. Collection of Law.

[3] Valouch, J.; Urbancokova, H. (2016). Methodology of Future Security Studies, The Proposal of New Prognostic Method for the Creation of Security Forecasts. Proceesings of SECURWARE 2016: The Tenth International Conference on Emerging Security Information, Systems and Technologies, July 24 - 28, Nice, France, ISBN 978 1-61208-493-0, pp. 69 - 71.

[4] Eichler, J. (2006). International security in the early 21st century. Prague: DoD CR, AVIS, 304 p. ISBN 80-7278362-2, Czech Republic

[5] Brehovska, L. (2017). Approach to Assessing the Preparedness of Hospital to the Power Outages. Transactions of VSB - Technical University of Ostrava, Vol. 7, No. 1, pp. 30 - 40, ISSN 1805-3238

[6] Rehak, D., Martinek, B. \& Ruzickova, P. (2015). Protection of the population in the context of current security threats, Ostrava: SPBI Spektrum, ISBN 978-80-7385-169-9, Czech Republic

[7] Sena, A., Corvalan, C. \& Ebi, K. (2014). Climate Change, Extreme Weather and Climate Events, and Health Impacts. In: Global Environmental Change, Vol. 1, pp. 605 - 613, Springer, ISBN 978-94-007-5784-4, Dordrecht

[8] Blakie, P., Cannon, T., et al. (1994). At risk: natural hazards, people's vulnerability, and disasters. Routledge, London

[9] Jie, 1. Jian-hua, J. \& Ming-hao, L. (2001). Hazard analysis system of urban post-earthquake fire based on GIS. ACTA SEISMOLOGICA SINICA, Vol. 14, No. 4, pp. 448 - 455, ISSN 0253-3782

[10] Heidaranlu, E., Ebadi, A. et al. (2015). Hospital Disaster Preparedness Tools: a Systematic Review. PLoS Currents, Vol. 1, pp. 1 - 19, ISSN 2157-3999

[11] Djalali, A., Hosseinijenab, V. et al. (2009). A fundamental, national, medical disaster management plan: an education-based model. Prehosp Disaster Med, Vol. 24, No. 6, pp. 565 - 569, ISSN 1049-0231

[12] Mareš, M., Rektorik, J. et al. (2013). Crisis Management: Security Case Study, Ekopress, ISBN 978-80-86929-927, Czech Republic

[13] Brehovska, L. (2011). Blackout. Kontakt, Vol. 13, No. 1, pp. 107 - 111, ISSN 1212-4117

[14] Below, R.; Wallemacq, P. (2018) Annual Disaster Statistical Review 2017, CRED

[15] Security Strategy of the Czech Republic (2015) Ministry of Foreign Affairs of the Czech Republic, Prague, ISBN 978-80-7441-005-5, Czech Republic

[16] Paulus, F. et al. (2015). Analysis of Threats for the Czech Republic, Czech Republic

[17] Internal security strategy for the European Union (2010). ISBN 978-92-824-2679-1, Belgium

[18] Trump, D. (2017). National Security Strategy of President Trump, USA

[19] Prochazkova, D.; Prochazka, J.; Rusko, M.; Mikulova, M. \& Ilko, J. (2017). Model for Critical Infrastructure Safety Management, Proceedings of the 28th DAAAM International Symposium, pp.0602-0610, B. Katalinic (Ed.), Published by DAAAM International, ISBN 978-3-902734-11-2, ISSN 1726-9679, Vienna, Austria 